\title{
Periodicidade de Realização do Exame Preventivo do Câncer do Colo do Útero
}

\author{
Frequency for taking a pap smear test for cervic cancer control
}

A realização do exame citopatológico de Papanicolaou tem sido reconhecida mundialmente como uma estratégia segura e eficiente para a detecção precoce do câncer do colo do útero na população feminina e tem modificado efetivamente as taxas de incidência e mortalidade por este câncer.

A efetividade da deteç̧ão precoce do câncer do colo do útero por meio do exame de Papanicolaou, associada ao tratamento deste câncer em seus estádios iniciais, tem resultado em uma redução das taxas de incidência de câncer cervical invasor que pode chegar a $90 \%$, quando o rastreamento apresenta boa cobertura $(80 \%$, segundo a O rganização Mundial da Saúde - OMS) e é realizado dentro dos padrões de qualidade (Gustafsson et al., 1997).

Em 1988, o M inistério da Saúde, por meio do Instituto $\mathrm{N}$ acional de $\mathrm{C}$ âncer, realizou uma reunião de consenso, com a participação de diversos espertos internacionais, representantes das sociedades científicas e das diversas instâncias ministeriais e definiu que, no Brasil, o exame colpocitopatológico deveria ser realizado em mulheres de 25 a 60 anos de idade, ou que já tivessem tido atividade sexual mesmo antes desta faixa de idade, uma vez por ano e, após 2 exames anuais consecutivos negativos, a cada 3 anos.

Tal recomendação apóiz-se na observação da história natural do câncer do colo do útero, que permite a detecção precoce de lesões pré-neoplásicas e o seu tratamento oportuno, graças à lenta progressão que apresenta para doença mais grave.

0 câncer do colo do útero iniciasse a partir de uma lesão pré-invasiva, curável em até $100 \%$ dos casos (anormalidades epiteliais conhecidas como displasia e carcinoma in stu ou diferentes graus de neoplasia intraepitelial cervical [NIC]), que normalmente progride lentamente, por anos, antes de atingir o estágio invasor da doença, quando a cura se torna mais difícil, quando não impossível (Figura 1).

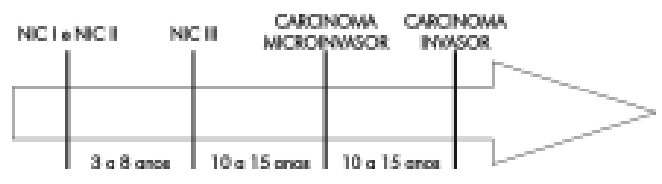

Figura 1. Seqüência típica de eventos na história natural do câncer do colo do útero (Fonte: WH O, 1988).

Barron e Richart (1968) mostraram que, na ausência de tratamento, o tempo mediano entre a detecção de uma displasia leve (H PV, NIC I) e o desenvolvimento de carcinoma in situ é de 58 meses, enquanto para as displasias moderadas (N IC II) este tempo éde 38 meses e, nas displasias graves (N IC III), de 12 meses. Em geral, estima-se que a grande maioria das lesões de baixo grau regredirão espontaneamente, enquanto cerca de $40 \%$ das lesões de alto grau não tratadas evoluirão para câncer invasor em um período médio de 10 anos (Sawaya et al., 2001). Por outro lado, o Instituto Nacional de Câncer dos Estados Unidos $(\mathrm{N} \mathrm{Cl}, 2000)$ calcula que somente $10 \%$ dos casos de carcinoma in situ evoluirão para câncer invasor no primeiro ano, enquanto que $30 \%$ a $70 \%$ terão evoluído decorridos 10 a 12 anos, caso não seja oferecido tratamento.

Segundo a OM S, estudos quantitativos têm demonstrado que, nas mulheres entre 35 e 64 anos, depois de um exame citopatológico do colo do útero negativo, um exame subseqüente pode ser realizado a cada 3 anos, com a mesma eficácia da realização anual. 
Conforme apresentado na tabela abaixo, a expectativa de redução percentual no risco cumulativo de desenvolver câncer, após um resultado negativo, é praticamente a mesma, quando o exame é realizado anualmente (redução de $93 \%$ do risco) ou quando ele é realizado a cada 3 anos (redução de $91 \%$ do risco). Verifica-se ainda que, mesmo se realizado a cada 10 anos, o rastreamento reduz a incidência de carcinoma cervical em pelo menos 2/3, o que apóia a recomendação da OMS de que países que precisam implementar o controle do câncer do colo do útero a curto prazo, o exame citopatológico se realize apenas uma vez, nas mulheres entre 35 e 40 anos de idade.

Tabela 1. Efeito protetor do rastreamento para câncer do colo do útero após um exame negativo, em mulheres de 35 a 64 anos (Fonte: van Oortmarssen et al., 1992).

\begin{tabular}{cc}
$\begin{array}{c}\text { Intervalo entre os } \\
\text { exames }\end{array}$ & Redução na incidência cumulativa \\
1 ano & $93 \%$ \\
\hline 2 anos & $93 \%$ \\
\hline 3 anos & $91 \%$ \\
\hline 5 anos & $84 \%$ \\
\hline 10 anos & $64 \%$ \\
\hline
\end{tabular}

A experiência internacional tem mostrado uma importante redução nas taxas de incidência ajustadas pela população mundial, tal como apresentado na Tabela 2.

Tabela 2. Redução nas taxas de incidência do câncer do colo do útero em programas de rastreamento em países nórdicos

(Fonte: European Commission Europe Against Cancer, 2000).

\begin{tabular}{cc}
$\begin{array}{c}\text { Intervalo entre os } \\
\text { exames }\end{array}$ & $\begin{array}{c}\text { Redução nas taxas de incidência* } \\
\text { entre } 1986 \text { e } 1995\end{array}$ \\
\hline Islândia & $67 \%$ \\
\hline Finlândia & $75 \%$ \\
\hline Suécia & $55 \%$ \\
\hline Dinamarca & $54 \%$ \\
\hline Noruega & $34 \%$ \\
\hline *Taxas de incidência ajustadas pela população mundial
\end{tabular}

Com base nas evidências científicas disponíveis, a maioria dos países europeus e organismos norte-americanos vêem recomendando a realização do exame citopatológico do colo do útero a cada 3 anos, conforme apresentado na Tabela 3.
Tabela 3. Periodicidade de recomendação do exame citopatológico por diferentes programas de rastreamento da União Européia e América do Norte (Fonte: Linos \& Riza, 2000).

\begin{tabular}{|c|c|}
\hline Periodicidade & Países \\
\hline \multirow{7}{*}{ Anual } & Áustria, Alemanha, Luxemburgo, Sociedade \\
\hline & Americana de Câncer*, Academia Americana \\
\hline & de Médicos de Família*, Associação Médica \\
\hline & Americana* ${ }^{*}$ Colégio Americano de Obstetras e \\
\hline & Ginecologistas*, Instituto Nacional de Câncer \\
\hline & dos Estados Unidos*, Colégio Americano de \\
\hline & Ginecologistas*. \\
\hline \multirow{4}{*}{ A cada 3 anos } & $\begin{array}{l}\text { Bélgica, Itália, Espanha, Suécia, Dinamarca, } \\
\text { Força Tarefa Canadense, Força Tarefa }\end{array}$ \\
\hline & Americana, França ${ }^{*}$, Portugal ${ }^{*}$ e Grécia*, \\
\hline & Colégio Americano de Médicos*, Colégio \\
\hline & Americano de Medicina Preventiva*. \\
\hline A cada 5 anos & Finlândia, Irlanda, Holanda e Inglaterra** \\
\hline
\end{tabular}

*A cada 2 ou 3 anos, após 2 resultados anuais consecutivos negativos, ** A cada 3 a 5 anos.

\section{COMENTÁRIOS}

A periodicidade trienal de realização do exame citopatológico do colo do útero, estabelecida pelo M inistério da Saúde do Brasil, em 1988, e recomendada pelo Viva Mulher - Programa $\mathrm{N}$ acional de Controle do Câncer do Colo do Útero e M ama, permanece atual e está em acordo com as recomendações dos principais programas internacionais. Segundo a OMS, após um resultado negativo, a realização trienal do exame é tão eficiente quanto a anual, no que diz respeito à redução das taxas de incidência por este câncer. Além disso, a recomendação de que a periodicidade seja trienal, somente após dois resultados consecutivos, obtidos em exames realizados com intervalo anual, permite identificar os casos nos quais possa ter ocorrido um resultado falso-negativo.

\section{BIBLIOGRAFIA}

Barron BA, Richart RM . A statistical model of the natural history of cervical carcinoma based on a prospective study of 557 cases. I N atl C ancer I nst 1968;41(6):1343-53.

European Commission Europe Against Cancer Programme. Evaluation and monitoring of screening programmes. Brussels, Luxembourg; 2000. 
Gustafsson L, Pontén J Z Zack M , Adami H O . International incidence rates of invasive cervical cancer after introduction of cytological screening. $C$ ancer Causes Control 1997;8(5):755-63.

Linos A, Riza E. C omparisons of cervical cancer screening programmes in European U nion. Eur J Cancer 2000;36:2260-5.

$\mathrm{N}$ ational Cancer Institute (U S). Physician statement: cervical cancer [online]. Availablefrom: URL: http://cancer.med.upenn.edu/pdq_html/1/ engl/100103-3.html\#Stage_0

Sawaya GF, Brown AD, Washington AE, Garber AM . Current approaches to cervical-cancer screening. N Engl J M ed 2001;344(21):1603-7.
U .S. D epartment of $H$ ealth and $H$ uman Services. Papanicolaou smear. In: U.S. D epartment of H ealth and $\mathrm{H}$ uman Services. Put prevention into practice: clinician's handbook of preventive services. 2nd ed. 1992.

van 0 ortmarssen GJ , H abbema JD , van Ballegooijen $M$. Predicting mortality from cervical cancer after negative smear test results. BM J 1992;305(6851):449-51.

WH O. Cytological screening in the control of cervical cancer: technical guidelines. Geneva; 1988. 